\title{
Pollen-induced allergic rhinitis in 1360 Italian children: Comorbidities and determinants of severity
}

Arianna Dondi ${ }^{1,2, *}$, Salvatore Tripodi ${ }^{3, *}$, Valentina Panetta ${ }^{4}$, Riccardo Asero ${ }^{5}$, Andrea Di Rienzo Businco ${ }^{3}$, Annamaria Bianchi ${ }^{6}$, Antonio Carlucci $^{6}$, Giampaolo Ricci ${ }^{1}$, Federica Bellini ${ }^{1}$, Nunzia Maiello $^{7}$, Michele Miraglia del Giudice ${ }^{7}$, Tullio Frediani ${ }^{8}$, Simona Sodano ${ }^{8}$, Iride Dello lacono ${ }^{9}$, Francesco Macri ${ }^{8}$, Valerio Massaccesi ${ }^{8}$, Carlo Caffarelli $^{10}$, Laura Rinaldi ${ }^{10}$, Maria Francesca Patria ${ }^{11}$, Elena Varin ${ }^{12}$, Diego Peroni ${ }^{13}$, Iolanda Chinellato ${ }^{13}$, Loredana Chini ${ }^{14}$, Viviana Moschese $^{14}$, Sandra' Lucarelli $^{8}$, Roberto Bernardini ${ }^{15}{ }^{\text {, Giuseppe Pingitore }}{ }^{16}$, Umberto Pelosi $^{17}$, Mariangela Tosca ${ }^{18}$, Francesco Paravati ${ }^{19}$, Stefania La Grutta ${ }^{20}$, Paolo Meglio ${ }^{21}$, Mauro Calvanín ${ }^{22}$, Mario Plebani ${ }^{23}$, Paolo Maria Matricardi ${ }^{24}$; the Italian Pediatric Allergy Network (I-PAN)

${ }^{1}$ Pediatric Unit, Department of Medical and Surgical Sciences, University of Bologna, Bologna, Italy; ${ }^{2}$ Pediatric Unit, Department for Mother and Child, Ramazzini Hospital, Carpi, Italy; ${ }^{3}$ Pediatric Allergology Unit, Sandro Pertini Hospital, Rome, Italy; ${ }^{4} L^{\prime}$ Altrastatistica srl, Consultancy and Training, Biostatistics Office, Rome, Italy; ${ }^{5}$ Allergology Service, San Carlo Clinic, Paderno Dugnano, Milan, Italy; ${ }^{6}$ Pediatric Unit, Mazzoni Hospital, Ascoli Piceno, Italy; ${ }^{7}$ Pediatric Department, Second University, Naples, Italy; ${ }^{8}$ Pediatric Department, La Sapienza University, Rome, Italy; ${ }^{9}$ Pediatric Unit, Fatebenefratelli Hospital, Benevento, Italy; ${ }^{10}$ Clinica Pediatrica Unit, Unit of Allergy and Immunology in Evolutive Age, Department of Clinical and Experimental Medicine, University of Parma, Parma, Italy; ${ }^{11}$ Pediatric Clinic 1, Department of Pathophysiology and Transplantation, University of Milan, Fondazione IRCCS Ca' Granda Ospedale Maggiore Policlinico, Milan, Italy; ${ }^{12}$ Pediatric Clinic 2, Fondazione IRCCS Ca' Granda Ospedale Maggiore Policlinico, Milan, Italy; ${ }^{13}$ Pediatric Unit, G.B. Rossi Hospital, Verona, Italy; ${ }^{14}$ Pediatric Department, Policlinico of Tor Vergata, Tor Vergata University, Rome, Italy; ${ }^{15}$ Pediatric Unit, San Giuseppe Hospital, Empoli, Italy; ${ }^{16}$ Pediatric Unit, Grassi Hospital, Rome, Italy; ${ }^{17}$ Pediatric Unit, Santa Barbara Hospital, Iglesias, Italy; ${ }^{18}$ Pulmonary Disease and Allergy Unit, G. Gaslini Hospital, Genoa, Italy; ${ }^{19}$ Pediatric Unit, Crotone, Italy; ${ }^{20} \mathrm{CNR}$ Institute of Biomedicine and Clinical Immunology, Palermo, Italy; ${ }^{21}$ Research Centre, San Pietro Hospital - Fatebenefratelli, Rome, Italy; ${ }^{22}$ Pediatric Unit, S. Camillo Forlanini Hospital, Rome, Italy; ${ }^{23}$ Department of Laboratory Medicine, University of Padua, Padua, Italy; ${ }^{24}$ Department of Pediatric Pneumology and Immunology, Charité Medical University, Berlin, Germany

To cite this article: Dondi A, Tripodi S, Panetta V, Asero R, Businco ADR, Bianchi A, Carlucci A, Ricci G, Bellini F, Maiello N, Miraglia del Giudice M, Frediani T, Sodano S, Dello lacono I, Macrì F, Massaccesi V, Caffarelli C, Rinaldi L, Patria MF, Varin E, Peroni D, Chinellato I, Chini L, Moschese V, Lucarelli S, Bernardini R, Pingitore G, Pelosi U, Tosca M, Paravati F, La Grutta S, Meglio P, Calvani M, Plebani M, Matricardi PM. Pollen-induced allergic rhinitis in 1360 Italian children: Comorbidities and determinants of severity. Pediatr Allergy Immunol 2013: 24: 742-751.

\section{Keywords}

allergic rhinitis; allergic conjunctivitis; asthma; children; epidemiology; Italy; multiple pollen syndrome; pan-allergens; profilin

\section{Correspondence}

Paolo M. Matricardi, Department of Paediatric Pneumology and Immunology, Charitè Medical University,

Augustenburgerplatz, 1, 13353 Berlin,

Germany

Tel.: +49 30450566406

Fax: +49 30450566931

E-mail: paolo.matricardi@charite.de

*These two authors equally contributed as first authors.

Accepted for publication 26 August 2013

DOI:10.1111/pai.12136

\begin{abstract}
Background: Pollen-induced allergic rhinoconjunctivitis (AR) is highly prevalent and rapidly evolving during childhood. General practitioners may not be fully aware of the nature and severity of symptoms experienced by patients and might underestimate the prevalence of moderate or severe disease. Thus, the relevance of early diagnosis and intervention may be overlooked.

Objectives: To investigate the severity of pollen-induced AR and its determinants in Italian children referred to allergy specialists and who had never received specific immunotherapy (SIT).

Methods: Children (age 4-18 yr) affected by pollen-induced AR who had never undergone SIT were recruited between May 2009 and June 2011 in 16 pediatric outpatient clinics in 14 Italian cities. Recruited children's parents answered standardized questionnaires on atopic diseases (International Study of Allergy and Asthma in Childhood, Allergic Rhinitis and its Impact on Asthma, Global Initiative for Asthma). The children underwent skin-prick test (SPT) with several airborne allergens and six food allergens. Information on socio-demographic factors, parental history of allergic diseases, education, perinatal events, breastfeeding, nutrition and environmental exposure in early life was collected through an informatics platform shared by the whole network of clinical centers (AllergyCARD ${ }^{\mathrm{TM}}$ ).

Results: Among the 1360 recruited patients (68\% males, age $10.5 \pm 3.4 \mathrm{yr}$ ), 695 $(51 \%)$ had moderate-to-severe AR, $533(39 \%)$ asthma, and $325(23.9 \%)$ oral allergy
\end{abstract}


syndrome (OAS). Reported onset of pollen-induced AR was on average at $5.3 \pm 2.8 \mathrm{yr}$, and its mean duration from onset was $5.2 \pm 3.3 \mathrm{yr}$. Only $6.2 \%$ of the patients were pollen-monosensitized, and $84.9 \%$ were sensitized to $\geq 3$ pollens. A longer AR duration was significantly associated with moderate-to-severe AR symptoms ( $\mathrm{p} 0.004)$, asthma ( $\mathrm{p} 0.030$ ), and OAS comorbidities $(\mathrm{p}<0.001)$.

Conclusions: This nationwide study may raise awareness of the severity of polleninduced AR among Italian children who have never received pollen SIT. The strong association between pollen-induced AR duration and several markers of disease severity needs replication in longitudinal studies, while suggesting that countrywide initiatives for earlier diagnosis and intervention should be planned.

Allergic rhino-conjunctivitis (AR) induced by pollens (polleninduced $A R$ ) is a very common allergic disease, affects millions of people globally (1), and is particularly prevalent among children (2). Patients' performance of daily activities, sleep patterns, cognitive function, work and school productivity, and quality of life are impaired (3). Less than half of the patients seek medical advice, and drug therapies generally achieve only partial control of symptoms (3). Specific immunotherapy (SIT) with pollen extracts can reduce symptoms and prevent subsequent asthma and is the only intervention that might modify the natural history of pollen-induced AR if properly and timely administered (4). Nevertheless, only a minority of eligible patients receive SIT (5). Recently, a panEuropean survey demonstrated that (primary health) physicians may not be fully aware of the nature and severity of symptoms experienced by patients and that they often underestimate the prevalence of moderate or severe disease (3). The reasons for such suboptimal management of pollen AR may change in different countries, and the local conditions should be examined. Unfortunately, countrywide epidemiological data on pollen-induced AR are scarce in most European countries, and information on the level of AR severity of the patients seen by allergy specialists is missing. To fill this gap, we investigated children referred to allergy specialists in Italy and who had never received SIT for their pollen-induced AR. To this end, we have used the 'Panallergens in Pediatrics' (PAN-PED) survey, a multicenter, countrywide study performed by the Italian Pediatric Allergy Network (I-PAN; 6, 7). Results of a pilot study of this project, focused on molecular aspects of $\operatorname{IgE}$ sensitization in 200 children living in Rome, have recently been published (8). Here, we report the analysis of the determinants of polleninduced AR severity in the whole population sample of 1360 children recruited by 16 I-PAN centers from 14 cities widely distributed across the country.

\footnotetext{
Abbreviations

ANOVA, analysis of variance; $A R$, allergic rhinitis; ARIA, Allergic Rhinitis and its Impact on Asthma; $\mathrm{Cl}$, confidence interval; GINA, Global Initiative for Asthma; I-PAN, Italian Pediatric Allergy Network; ISAAC, International Study of Allergy and Asthma in Childhood; OAS, oral allergy syndrome; PAN-PED, Panallergens in Pediatrics; SD, standard deviation; SIT, specific immunotherapy; SPT, skin-prick test.
}

\section{Materials and methods}

\section{Study population and study design}

Panallergens in Pediatrics (PAN-PED) is the first nationwide observational multicenter survey carried out by the I-PAN. I-PAN is a large group of Italian specialists in Pediatric Allergy, sharing informatics technology and acquiring useful scientific information from routine clinical practice $(6,7)$. The study aims at investigating the impact of sensitization to highly cross-reacting allergenic molecules on the diagnostic and therapeutic management of respiratory allergies in childhood. Children spontaneously seeking care were enrolled in 16 pediatric outpatient clinics in 14 Italian cities in Northern Italy (five centers: Milan, Genoa, Verona, Parma and Bologna), Central Italy (five centers: Empoli, Ascoli Piceno, Ostia and three in Rome), and Southern Italy (five centers: Naples, Benevento, Crotone, Cagliari and Palermo) between May 2009 and June 2011. Criteria for eligibility were as follows: (i) age 4$18 \mathrm{yr}$; (ii) a history of pollen-induced AR and/or asthma in one of the two last pollen seasons; (iii) positive skin-prick tests (SPT) for the relevant pollen extracts. Exclusion criteria were as follows: (i) previous SIT for any pollen allergen; (ii) any other severe chronic disease. Recruited children's parents answered a standardized questionnaire, and patients underwent SPT and a blood drawing. For the present analysis, only results obtained through the questionnaire and SPT in patients with AR have been considered. The PAN-PED study design and procedures have been approved by the ethical committee of all the participating centers. Parents or tutors of all participants gave an informed written consent to clinical investigations.

\section{Questionnaire and diagnostic criteria}

Questions obtained from the following internationally validated questionnaires were administered to all participants: International Study of Allergy and Asthma in Childhood (ISAAC; 9), Allergic Rhinitis and its Impact on Asthma (ARIA; 10), and Global Initiative for Asthma (GINA; 11). A diagnosis of pollen-induced AR was made as previously described (8) in the presence of: (i) nasal and/or eye symptoms (apart from cold) (9) for at least 3 weeks during one of the two last pollen seasons and (ii) positive SPT (wheal reaction of 
$3 \mathrm{~mm}$ or more) in accordance with clinical history and local pollination period. Pollen-induced AR was classified as mild or moderate/severe as well as intermittent or persistent according to the ARIA classification (10). Children with pollen-induced AR were also classified as sneezers or blockers (or unclassified) according to the same ARIA classification (10). The age at onset of pollen-induced AR was reported by the parents as their child's age at the first season with relevant symptoms. The duration of AR since its onset was established as the difference in years between the child's age at recruitment and the child's age at AR onset. The annual period of symptoms was defined as the months with symptoms in the 12 months preceding the recruitment visit. Asthma was classified as intermittent, mild persistent, moderate persistent, or severe persistent according to the GINA classification (12). Oral allergy syndrome (OAS) was defined as the occurrence of immediate oral itching with or without angioedema of the lips and or the tongue following the ingestion of the food (13). Reported immediate reaction to foods was defined by a positive answer to the following question: 'Have/has you/your child ever had immediate allergic reaction after ingestion of...?' Questions regarding sociodemographic factors, family history of allergic diseases, education, perinatal events, breast feeding and nutrition, and environmental exposure (tobacco smoke) in early life were asked. An informatics platform ('AllergyCARD ${ }^{\mathrm{TM}}$,' Technology Projects \& Software Productions [TPS], Rome, Italy) was used for data input.

\section{Skin-prick tests}

SPT were performed using a standard panel of commercial extracts (ALK-Abelló, Milan, Italy) of seasonal airborne allergens (Phleum pratense, Cynodon dactylon, pellitory, Plantago lanceolata, Chenopodium album, mugwort, Salsola kali, ragweed, cypress, birch, plane, Olea europaea, elm, hazel), food allergens (peach, apple, wheat, soybean, peanut, hazelnut), and latex. A commercial date palm pollen extract enriched in profilin (ALK-Abelló) was used to detect profilin sensitization (13). Histamine $0.1 \mathrm{mg} / \mathrm{ml}$ and glycerol solution were used as positive and negative controls, respectively. Morrow-Brown needles were used to prick the skin, and the wheal reactions were read after $15 \mathrm{~min}$. A wheal $\geq 3 \mathrm{~mm}$ after subtraction of the negative control was regarded as positive (14). Polysensitization to pollen allergens was defined as a positive response to at least three pollen allergenic sources.

\section{Statistics}

Data were summarized as numbers (n) and frequencies (\%) if data were categorical and as mean and standard deviation (SD) if data were quantitative. Patients were grouped in three geographic areas (North, Center, South) depending on the geographic position of their recruitment center. Chi-square and analysis of variance (ANOVA) were used to evaluate differences between the three geographic areas when data were categorical or quantitative, respectively. Chi-square was also used to compare, among children with pollen AR, those with asthma vs. those without asthma and those with AR vs. those without
AR, if data were categorical; if data were quantitative, Student's $t$-test was used. Two different multiple stepwise logistic regressions were applied to evaluate possible risk factors for a more severe AR, defined by a moderate-to-severe ARIA classification, by asthma and by OAS comorbidity. Only factors associated at univariate level $(\mathrm{p}<0.10)$ were included in this model. Adjusted odds ratio (OR) and its 95\% confidence interval (95\% CI) were calculated. A p-value $<0.05$ was considered statistically significant. STATA 12.1 (StataCorp LP, College Station, Texas, USA) was used for all analyses.

\section{Results}

\section{Study population and risk factors}

A total of 1360 patients $(68 \%$ males, mean age $10.5 \pm 3.4)$ were recruited, 405 of whom (30\%) from Northern Italy, 672 (49\%) from Central Italy and $283(21 \%)$ from Southern Italy. The vast majority $(96 \%)$ of the children were born from Italian, Caucasian parents. About one-fourth of the patients were only children, and $37 \%$ had older siblings. A history of atopic diseases in the biologic father or mother was reported by $529(39 \%)$ and $602(44 \%)$ of the patients, respectively. Only $5 \%$ of the mothers had smoked during pregnancy, while 538 $(40 \%)$ of the fathers and $314(23 \%)$ of the mothers were current smokers (Table 1).

\section{Characteristics of pollen AR}

The mean age at onset of pollen-induced AR was $5.3 \mathrm{yr}$ $(\mathrm{SD} \pm 2.8)$, and the mean disease duration since onset was $5.2 \mathrm{yr}(\mathrm{SD} \pm 3.3)$. Altogether, $994(73 \%)$ of the patients reported that their AR had started at least $3 \mathrm{yr}$ before, and 436 (32\%) reported at least $7 \mathrm{yr}$ before (Fig. 1a). According to the ARIA classification, 875 (64\%) AR patients were 'sneezers,' and $169(12 \%)$ were 'blockers,' while for the remaining 316 $(23 \%)$ children, no category could be assigned. AR was mild in $49 \%$ (665) of the patients, whereas a moderate-to-severe form was observed in $695(51 \%)$. As expected, most patients had AR symptoms during spring and a smaller proportion in early autumn (Fig. 1b). Overall, 533 patients (39\%) had asthma comorbidity. Among the group of 533 asthmatic patients, the mean age at onset of asthma was $5.0 \mathrm{yr}(\mathrm{SD} \pm 3.1)$. Intermittent asthma was the most frequent category of asthma, while only 33 children $(2 \%)$ were affected by severe asthma. Asthma was uncontrolled in 217 patients, partially controlled in 225, and well controlled in only 116 patients (Table 1).

\section{Allergic symptoms to plant-derived foods}

OAS was reported by $325(24 \%)$ of the patients. About one-third and one-fifth of the patients reported a history of atopic dermatitis and urticaria/angioedema, respectively. Anaphylaxis was reported by $77(6 \%)$ patients (Table 1). Allergic reactions triggered by a plant-derived food were reported by $384(28 \%)$ patients. The plant-derived food most frequently reported to be a cause of allergic reactions was kiwi, followed by Rosaceae (peach and apple) and nuts (hazelnut, peanut, and walnut) (Fig. 1c). 
Table 1 Characteristics of the population sample

\begin{tabular}{|c|c|c|c|c|c|}
\hline & $\begin{array}{l}\text { All } \\
(N=1360)\end{array}$ & $\begin{array}{l}\text { North } \\
(N=405)\end{array}$ & $\begin{array}{l}\text { Center } \\
(N=672)\end{array}$ & $\begin{array}{l}\text { South and Islands } \\
(N=283)\end{array}$ & $p^{*}$ \\
\hline Males (n, \%) & $920(67.6)$ & $270(66.7)$ & $465(69.2)$ & $185(65.4)$ & ns \\
\hline Age (years) (mean, SD) & $10.5(3.4)$ & $10.5(3.5)$ & $10.5(3.4)$ & $10.2(3.4)$ & ns \\
\hline Siblings & $1006(74)$ & $264(65.2)$ & $500(74.4)$ & $242(85.5)$ & $<0.001$ \\
\hline Older (n, \%) & $499(36.7)$ & $125(30.9)$ & $258(38.4)$ & $116(41)$ & 0.011 \\
\hline Younger (n, \%) & $594(43.7)$ & $167(41.2)$ & $278(41.4)$ & $149(52.7)$ & 0.003 \\
\hline \multicolumn{6}{|l|}{ Familial atopy } \\
\hline Father (n, \%) & $529(38.9)$ & $182(44.9)$ & $230(34.2)$ & $117(41.3)$ & 0.001 \\
\hline Mother (n, \%) & $602(44.3)$ & $195(48.1)$ & $287(42.7)$ & $120(42.4)$ & ns \\
\hline \multicolumn{6}{|l|}{ Smoke exposure } \\
\hline Father (n, \%) & 538 (39.6) & $153(37.8)$ & $262(39)$ & $123(43.5)$ & ns \\
\hline Mother (n, \%) & $314(23.1)$ & $98(24.2)$ & $163(24.3)$ & $53(18.7)$ & ns \\
\hline \multicolumn{6}{|l|}{ Allergic rhinitis (n, \%) } \\
\hline Age at onset (years) (mean, SD) & $5.3(2.8)$ & $5.1(2.6)$ & $5.8(3.0)$ & $4.4(2.4)$ & $<0.001$ \\
\hline Disease duration (years) (mean, SD) & $5.2(3.3)$ & $5.4(3.4)$ & $4.8(3.2)$ & $5.8(3.4)$ & $<0.001$ \\
\hline Months/year with symptoms (mean, SD) & $4.3(1.8)$ & $3.9(1.7)$ & $4.3(2.0)$ & $4.9(1.3)$ & $<0.001$ \\
\hline \multicolumn{6}{|l|}{$\begin{array}{l}\text { Allergic Rhinitis and its Impact on Asthma } \\
\text { ARIA classification (quality) }\end{array}$} \\
\hline Sneezers $(n, \%)^{\dagger}$ & $875(64.3)$ & $173(42.7)$ & $495(73.7)$ & $207(73.1)$ & $<0.001$ \\
\hline Blockers $(n, \%)^{\dagger}$ & 169 (12.4) & $55(13.6)$ & $68(10.1)$ & $46(16.3)$ & \\
\hline \multicolumn{6}{|l|}{ ARIA classification (severity) } \\
\hline Mild $(n, \%)$ & $665(48.9)$ & $262(64.7)$ & $285(42.4)$ & $118(41.7)$ & $<0.001^{\S}$ \\
\hline Intermittent (n, \%) & $353(26)$ & $178(44)$ & $136(20.2)$ & $39(13.8)$ & \\
\hline Persistent (n, \%) & $312(22.9)$ & $84(20.7)$ & $149(22.2)$ & 79 (27.9) & \\
\hline Moderate-severe (n, \%) & $695(51.1)$ & $143(35.3)$ & $387(57.6)$ & $165(58.3)$ & \\
\hline Intermittent (n, \%) & $136(10)$ & 43 (10.6) & $81(12.1)$ & $12(4.24)$ & \\
\hline Persistent $(n, \%)$ & $559(41.1)$ & $100(24.7)$ & $306(45.5)$ & $153(54.1)$ & \\
\hline Asthma $(n, \%)$ & $533(39.2)$ & 202 (49.9) & $232(34.5)$ & $99(35)$ & $<0.001$ \\
\hline Age at onset (years) (mean, SD) & $5.0(3.1)$ & $4.9(2.9)$ & $5.4(3.4)$ & $3.9(2.6)$ & $<0.001$ \\
\hline \multicolumn{6}{|l|}{ GINA classification } \\
\hline Intermittent (n, \%) & $327(24)$ & $119(29.4)$ & $147(21.9)$ & $61(21.6)$ & 0.001 \\
\hline Mild persistent (n, \%) & $72(5.29)$ & $20(4.94)$ & 47 (6.99) & $5(1.77)$ & \\
\hline Moderate persistent (n, \%) & $62(4.56)$ & $25(6.17)$ & $27(4.02)$ & $10(3.53)$ & \\
\hline Severe persistent (n, \%) & $33(2.43)$ & 19 (4.69) & $6(0.89)$ & $8(2.83)$ & \\
\hline \multicolumn{6}{|l|}{ Control } \\
\hline Good (n, \%) & $106(7.79)$ & $35(8.64)$ & $52(7.74)$ & $19(6.71)$ & ns \\
\hline Partial $(n, \%)$ & $210(15.4)$ & $86(21.2)$ & $88(13.1)$ & $36(12.7)$ & \\
\hline Uncontrolled (n, \%) & $217(16)$ & $81(20)$ & $92(13.7)$ & $44(15.5)$ & \\
\hline \multicolumn{6}{|l|}{ Other allergy symptoms } \\
\hline Oral allergy syndrome (n, \%) & $325(23.9)$ & 125 (30.9) & $153(22.8)$ & $47(16.6)$ & $<0.001$ \\
\hline Anaphylaxis (n, \%) & 77 (5.66) & $36(8.89)$ & $25(3.72)$ & $16(5.65)$ & 0.002 \\
\hline Urticaria/angioedema (n, \%) & 270 (19.9) & $114(28.1)$ & $82(12.2)$ & $74(26.1)$ & $<0.001$ \\
\hline Atopic dermatitis (n, \%) & $488(35.9)$ & 202 (49.9) & $156(23.2)$ & $130((45.9)$ & $<0.001$ \\
\hline Gastrointestinal symptoms (n, \%) & $90(6.62)$ & $45(11.1)$ & $26(3.87)$ & $19(6.71)$ & $<0.001$ \\
\hline
\end{tabular}

*Chi-square test was used comparing frequencies; ANOVA test comparing means.

†Three hundred and sixteen patients could not be classified neither as sneezers nor as blockers according to Allergic Rhinitis and its Impact on Asthma (ARIA) criteria.

"In 39 subjects, asthma could not be classified according to Global Initiative for Asthma (GINA) criteria due to missing values.

${ }^{\S}$ Mild vs. moderate-severe.

\section{Sensitization to pollens and food allergens}

The vast majority of the patients were polysensitized (Fig. 1d). Pollen monosensitization was observed in $6.2 \%$ of the patients, while $84.9 \%$ and $52.9 \%$ of them were sensitized to at least 3 or 6 pollen extracts, respectively (Table 2,
Fig. 1d). The vast majority of the patients (89\%) were sensitized to timothy grass (Phleum pratense). Sensitization to olive tree pollen was also very frequent $(60 \%)$, while $37 \%$, $34 \%$, and $22 \%$ were sensitized to birch, pellitory, and ragweed, respectively (Table 2). Overall, $55 \%$ of patients were sensitized to at least one of the six examined food 
(a)

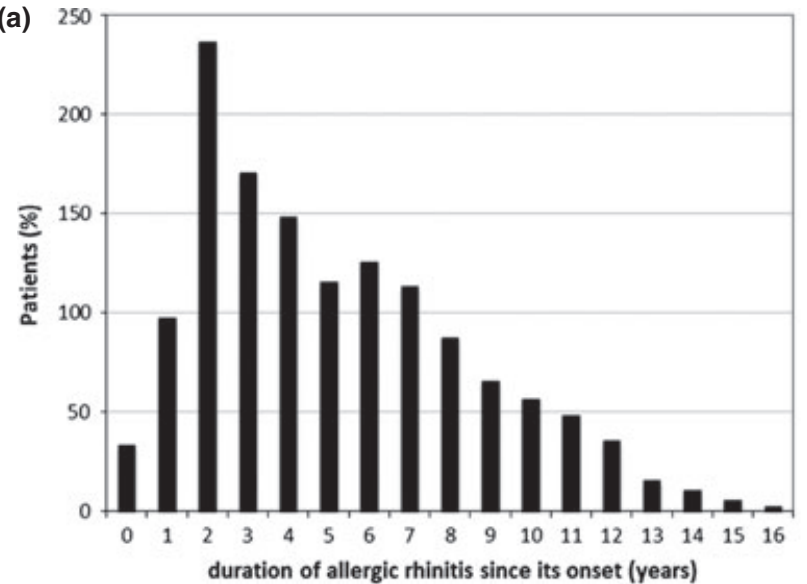

(c)

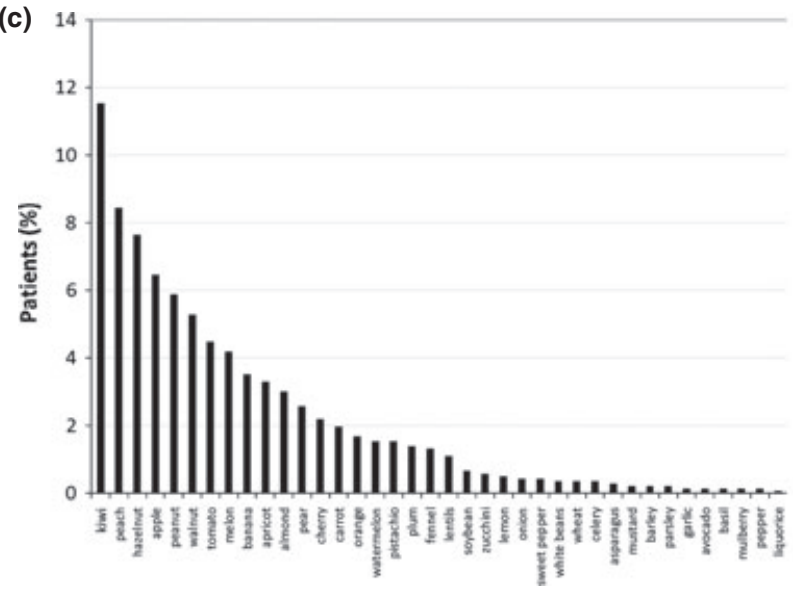

(b) 100

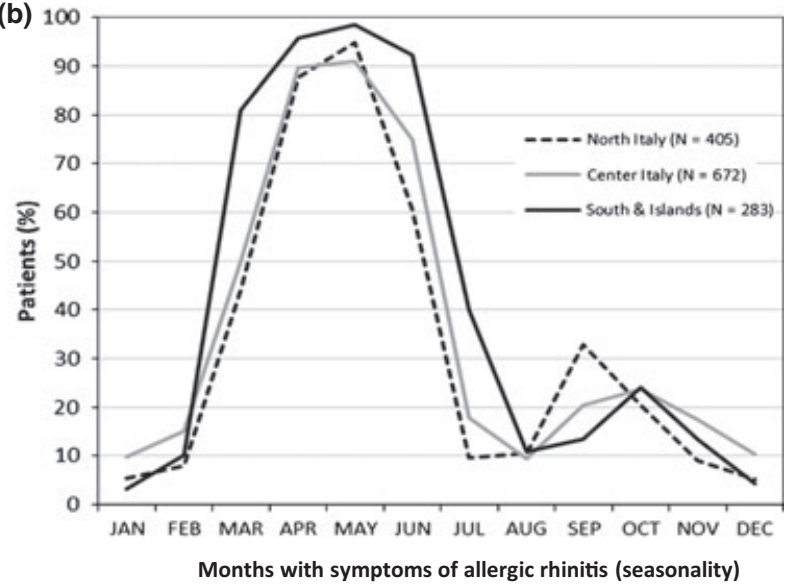

(d)

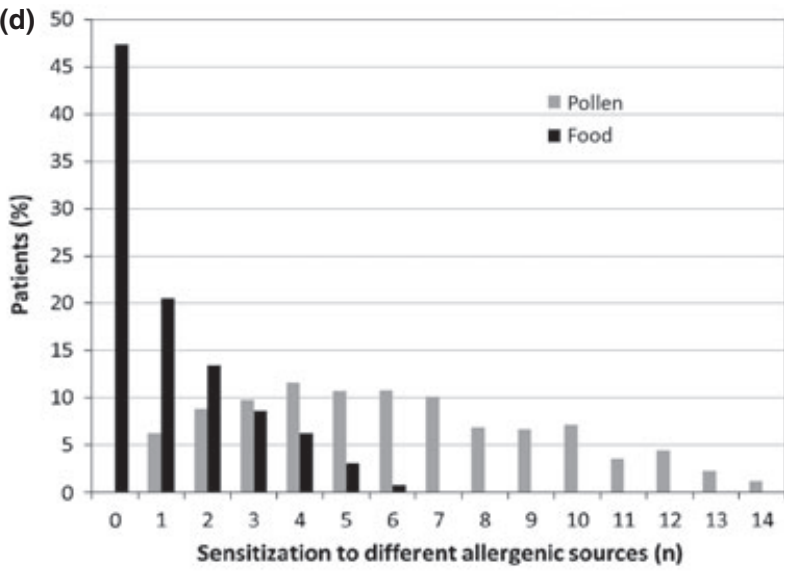

Figure 1 Frequency distribution of different parameters in a population of 1360 children affected by pollen-induced allergic rhinoconjunctivitis (AR) and/or asthma: (a) duration of AR (years); (b) months with symptoms, by geographic areas; (c) lifetime immediate food reactions as reported by patients, parents, and/or caregivers (d) number of sensitizations for pollens and foods.

extracts (apple, peach, wheat, soy, peanut, hazelnut). The most frequent skin reaction on SPT was observed against peanuts $(30 \%)$ and hazelnuts $(25 \%)$. About one-fourth of the patients reacted to date palm profilin, while only a tiny fraction $(2 \%)$ was sensitized to latex. The number of positive SPT reactions was higher among the patients sensitized than in those not sensitized to profilin $(8.6 \pm 3.0$ vs. $5.1 \pm 2.9$; $\mathrm{p}<0.001)$.

\section{Geographic differences}

Statistically significant differences across geographic areas were identified (Table 1). Children recruited in Northern Italy had more frequently asthma and OAS comorbidity and a lower frequency of moderate-to-severe disease (Table 2, Fig. 2), while those recruited in the Southern regions had an earlier disease onset and a longer disease duration. The mean number of months with symptoms during the year grew with a northsouth gradient from $3.9(\mathrm{SD} \pm 1.7)$ months in the North to 4.9 $(\mathrm{SD} \pm 1.3)$ months in the South $(\mathrm{p}<0.001)$. Accordingly, in Southern Italy the springtime extension of AR symptoms was longer (Fig. 1b). Patients recruited in Northern Italy were more frequently sensitized to the pollens of Phleum pratense, Cynodon dactylon, birch, hazel, and ragweed. Similarly, polysensitization to pollens and sensitization to date palm profilin, peanut, hazelnut, and soybean were more common in the North. By contrast, skin sensitization to olive, cypress, and pellitory pollens was more frequent in Central and Southern Italy (Table 2, Fig. 2).

\section{Factors affecting the severity of pollen-induced AR}

A univariate analysis was used to search for risk factors of a higher severity of symptoms (moderate-to-severe AR) and of asthma or OAS comorbidity. A few risk factors, including age, older siblings, a smoking father, a longer disease duration since onset, and a broader seasonal duration of symptoms, were associated with moderate-to-severe pollen-induced AR; an atopic mother, earlier disease onset, longer disease duration since onset, a broader seasonal duration of symptoms, and a 'blocker' phenotype were associated with asthmatic comorbidity; last, male gender, smoking parents, and a longer disease duration since onset were associated with OAS in univariate analysis (Table 3). 
Table 2 Atopic sensitization to airborne and vegetable food allergens in 1360 Italian children

\begin{tabular}{|c|c|c|c|c|c|}
\hline Allergenic extract & $\begin{array}{l}\text { All } \\
(N=1360) \%\end{array}$ & $\begin{array}{l}\text { North } \\
(N=405) \%\end{array}$ & $\begin{array}{l}\text { Center } \\
(\mathrm{N}=672) \%\end{array}$ & $\begin{array}{l}\text { South \& Islands } \\
(N=283) \%\end{array}$ & $p^{*}$ \\
\hline \multicolumn{6}{|l|}{ Pollen } \\
\hline P. pratense & 89.6 & 95.1 & 90.6 & 79.5 & $<0.001$ \\
\hline C. dactylon & 70.2 & 80.7 & 71.1 & 52.7 & $<0.001$ \\
\hline Olive tree & 59.6 & 51.6 & 63.4 & 62.2 & $<0.001$ \\
\hline P. lanceolata & 58.8 & 70.1 & 55.1 & 51.6 & $<0.001$ \\
\hline C. album ${ }^{\dagger}$ & 64.4 & 69.4 & 68.9 & 50.5 & $<0.001$ \\
\hline Cypress & 41.4 & 23.7 & 55.5 & 33.2 & $<0.001$ \\
\hline Birch & 37.1 & 49.1 & 34.7 & 25.8 & $<0.001$ \\
\hline Plane & 34.2 & 36.1 & 34.8 & 30.0 & 0.233 \\
\hline Pellitory & 34.3 & 19.8 & 37.8 & 46.6 & $<0.001$ \\
\hline Hazel $^{\dagger}$ & 39.9 & 54.1 & 36.7 & 24.7 & $<0.001$ \\
\hline Mugwort & 24.4 & 26.9 & 19.2 & 33.2 & $<0.001$ \\
\hline Salsola ${ }^{\dagger}$ & 25.1 & 31.1 & 22.0 & 20.9 & 0.002 \\
\hline Ambrosia $^{\dagger}$ & 22.5 & 27.4 & 22.1 & 15.9 & 0.002 \\
\hline $\mathrm{Holm}^{\dagger}$ & 7.7 & 12.5 & 5.1 & 4.6 & $<0.001$ \\
\hline$\geq 3$ pollens ${ }^{\dagger}$ & 83.5 & 87.2 & 83.6 & 77.7 & 0.005 \\
\hline$\geq 6$ pollens $^{\dagger}$ & 49.3 & 58.0 & 46.3 & 44.2 & $<0.001$ \\
\hline \multicolumn{6}{|l|}{ Food } \\
\hline Peanut & 30.0 & 34.6 & 26.9 & 30.7 & 0.029 \\
\hline Hazelnut & 25.6 & 36.1 & 20.1 & 23.7 & $<0.001$ \\
\hline Peach & 19.6 & 12.6 & 16.1 & 37.8 & $<0.001$ \\
\hline Wheat & 18.8 & 26.4 & 8.9 & 31.1 & $<0.001$ \\
\hline Apple & 15.8 & 10.4 & 14.0 & 27.9 & $<0.001$ \\
\hline Soybean & 8.7 & 14.6 & 5.8 & 7.1 & $<0.001$ \\
\hline$\geq 3$ foods & 18.8 & 21.23 & 13.8 & 26.86 & $<0.001$ \\
\hline Profiline & 24.9 & 34.3 & 21.6 & 19.1 & $<0.001$ \\
\hline Latex $^{\dagger}$ & 1.9 & 1.5 & 2.3 & 1.8 & 0.666 \\
\hline
\end{tabular}

${ }^{*} \mathrm{p}$-value is referred to the comparison among Northern, Central and Southern Italy.

${ }^{\dagger}$ All $(n=1110)$, Center $(n=422)$.

A stepwise regression analysis was then performed to ascertain whether some of the above-mentioned factors were primarily associated with the markers of severity of polleninduced AR (Table 4). In this model, each year of disease duration since onset was associated with higher odds of moderate-to-severe pollen-induced AR (OR 1.06, 95\% CI $1.02-1.11 ; \mathrm{p}$ 0.004), asthma comorbidity (OR 1.05, 95\% CI 1.00-1.09; p 0.030), and OAS comorbidity (OR 1.08, 95\% CI $1.04-1.12 ; \mathrm{p}<0.001)$. In keeping with the stepwise regression analysis, we observed that the risks of more severe polleninduced AR, asthma, and OAS comorbidity, as well as a broader duration of seasonal symptoms, and polysensitization were all increasing with the duration of pollen-induced AR since its reported onset (Fig. 3).

\section{Discussion}

We examined 1360 children with pollinosis seeking care at 16 Italian pediatric allergy centers and who had never received SIT for their disease. Our major findings include the following: (i) a quite long average reported disease duration (over $5 \mathrm{yr}$ at recruitment); (ii) a high frequency of moderate-to-severe disease $(51 \%)$, asthma comorbidity (39\%), OAS $(24 \%)$, and a very high degree of heavy polysensitization ( $\geq 6$ positive SPT)
(53\%); (iii) an association between longer disease duration from its onset and the selected markers of disease severity; (iv) a higher severity and a broader extension of symptoms in Southern Italy, balanced by a more frequent birch and plantderived food sensitization as well as of OAS and asthma in Northern Italy. These data indicate that pollen-induced AR is in an advanced stage in a large proportion of children seeking care at the participating Italian allergy centers. They also may imply that, for many of these patients, a long time-lag might have occurred between disease onset and the clinical evaluation by a specialist.

In this study, we have used many different markers of disease severity: a validated classification (ARIA), asthma and OAS comorbidity, the extension of the seasonal period with symptoms, and the number of pollens eliciting a positive skin wheal reaction. All these parameters consistently showed that the level of severity of pollen-induced AR in the study population is high. A longitudinal study (15) has recently shown that the immunologic response causing pollen-induced $\mathrm{AR}$ is a progressive process starting simple and becoming more intense and complex with time. Therefore, it may be speculated that, for many patients, the disease would have been less severe if they had been referred to the specialized centers immediately after the onset of their pollen-induced AR and not after many 


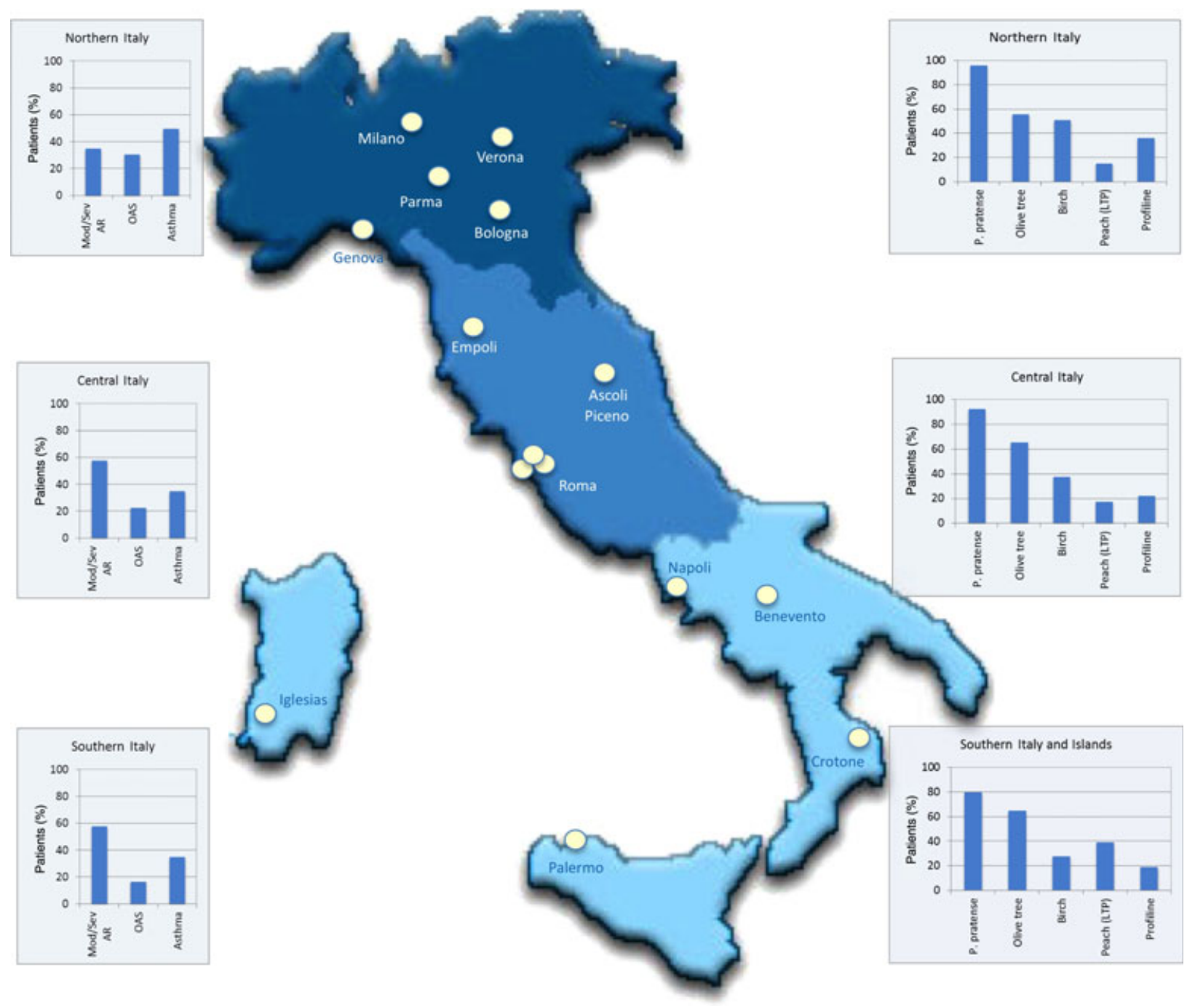

Figure 2 Map of Italy showing the location of the recruiting centers and the differences across the country (North, Center, South, and Islands). Left graphs: clinical features. Right graphs: sensitization examined with SPT.

years. Accordingly, the observed associations suggest that in most children the disease process had had enough time to become more and more complex through the years before their participation to this study. It could be also argued that these patients should have been treated earlier in the attempt to prevent their disease progression, both to prevent asthma (16) and to possibly block the biologic process that enhances the allergic sensitization to different sources and thus also induce OAS, even if the latter point needs more studies to be proven.

In our study, about every fourth child suffered from OAS (Table 1). This high prevalence was paralleled by a high prevalence of sensitivity to profilin, as reported in Table 2. Therefore, we tend to consider this high OAS prevalence a genuine one, rather than due to overreporting of symptoms. OAS is more frequent in adults but is also becoming more and more common in children with pollen allergy (17). Our observation may be consistent with the overall raising trend of food allergies, now known as 'the second wave of the allergy epidemic' (18). We speculate that OAS is not only becoming more frequent, but also that its onset (once more typical of adulthood) is being anticipated to childhood. To our knowledge, no observational longitudinal studies have so far examined the incidence of OAS in pollen-allergic children. On the other hand, one of us has shown that SIT may treat OAS in birch-allergic patients (19), and this observation has been replicated in some trials, but not in others. By contrast, no intervention study has addressed the hypothesis that early treatment (with SIT) can prevent the onset of OAS in children.

In Italy, the role of environmental factors as determinants for AR has recently been confirmed by an epidemiological study in which female gender, environmental smoke exposure, mold/dampness exposure, traffic exposure, current asthma, eczema, and the highest atopy index classes are significant risk factors for the disease (20). In the present analysis, we found also remarkable geographic differences in the frequencies of sensitization to birch and ragweed (higher in Northern Italy) 
Table 3 Relationship of risk factors with higher symptom severity, asthma and oral allergy syndrome (OAS) comorbidities in 1360 Italian children with pollen allergic rhinoconjunctivitis

\begin{tabular}{|c|c|c|c|c|c|c|c|c|c|}
\hline & $\begin{array}{l}\text { Mild } \\
(\mathrm{N}=665)\end{array}$ & $\begin{array}{l}\text { Moderate or } \\
\text { severe } \\
(\mathrm{N}=695)\end{array}$ & $p$ & $\begin{array}{l}\text { No asthma } \\
(\mathrm{N}=827)\end{array}$ & $\begin{array}{l}\text { With asthma } \\
(N=533)\end{array}$ & $p$ & $\begin{array}{l}\text { No OAS } \\
(\mathrm{N}=1035)\end{array}$ & $\begin{array}{l}\text { With OAS } \\
(N=325)\end{array}$ & $\mathrm{p}$ \\
\hline Males (n, \%) & $451(68)$ & $469(67)$ & ns & $558(67)$ & $362(68)$ & ns & $723(70)$ & $197(61)$ & 0.002 \\
\hline $\begin{array}{l}\text { Age (years) } \\
\text { (mean, SD) }\end{array}$ & $10.1(3.4)$ & $10.8(3.4)$ & $<0.001$ & $10.4(3.5)$ & $10.5(3.3)$ & ns & $10.3(3.4)$ & $10.9(3.6)$ & 0.003 \\
\hline Siblings & & & & $614(74)$ & $392(74)$ & ns & $774(75)$ & $232(71)$ & ns \\
\hline Older $(n, \%)$ & $211(32)$ & $288(41)$ & $<0.001$ & 302 (37) & $197(37)$ & ns & 379 (37) & $120(37)$ & ns \\
\hline Younger (n, \%) & $296(45)$ & $298(43)$ & ns & $366(44)$ & $228(43)$ & ns & $462(45)$ & $132(41)$ & ns \\
\hline \multicolumn{10}{|l|}{ Familial atopy } \\
\hline Father (n, \%) & $269(40)$ & 260 (37) & ns & 310 (37) & $219(41)$ & ns & 392 (38) & 137 (42) & ns \\
\hline Mother (n, \%) & $289(43)$ & $313(45)$ & ns & $348(42)$ & $254(48)$ & 0.043 & $445(43)$ & $157(48)$ & ns \\
\hline \multicolumn{10}{|l|}{ Smoke exposure } \\
\hline Father (n, \%) & $244(37)$ & 401 (58) & 0.034 & 324 (39) & $214(40)$ & ns & 394 (38) & $144(44)$ & 0.045 \\
\hline Mother (n, \%) & $141(21)$ & $173(25)$ & ns & $179(22)$ & $135(25)$ & ns & $218(21)$ & $96(30)$ & 0.002 \\
\hline \multicolumn{10}{|l|}{ Allergic rhinitis (n, \%) } \\
\hline $\begin{array}{l}\text { Age at onset } \\
\text { (years) (mean, SD) }\end{array}$ & $5.2(2.6)$ & $5.3(3.1)$ & ns & $5.6(3.0)$ & $4.8(2.5)$ & $<0.001$ & $5.3(2.7)$ & $5.2(3.1)$ & ns \\
\hline $\begin{array}{l}\text { Disease duration } \\
\text { (years) (mean, SD) }\end{array}$ & $4.9(3.4)$ & $5.4(3.3)$ & 0.006 & $4.8(3.2)$ & $5.8(3.4)$ & $<0.001$ & $5.0(3.3)$ & $5.8(3.4)$ & $<0.001$ \\
\hline $\begin{array}{l}\text { Months/year with } \\
\text { symptoms (mean, SD) }\end{array}$ & $3.9(1.7)$ & $4.6(1.8)$ & $<0.001$ & $4.2(1.7)$ & $4.4(2.0)$ & 0.014 & $4.3(1.8)$ & $4.4(1.8)$ & ns \\
\hline \multicolumn{10}{|l|}{$\begin{array}{l}\text { Allergic Rhinitis } \\
\text { and its Impact } \\
\text { on Asthma } \\
\text { classification (quality)* }\end{array}$} \\
\hline Sneezers $(n, \%)$ & $352(82)$ & $523(85)$ & ns & $548(87)$ & $327(79)$ & $<0.001$ & $661(64)$ & $214(66)$ & ns \\
\hline Blockers (n, \%) & 75 (18) & $94(15)$ & & $81(13)$ & $88(21)$ & & $125(12)$ & $44(14)$ & \\
\hline
\end{tabular}

*Three hundred and fifteen patients could not be classified, of which 197 among not asthmatics and 118 among asthmatics.

Table 4 Multivariate analysis of the relationships between risk factors and markers of pollen allergic rhinoconjunctivitis (AR) severity in Italian children

\begin{tabular}{|c|c|c|c|c|c|c|c|c|c|}
\hline & \multicolumn{3}{|c|}{$\begin{array}{l}\text { Moderate-to-severe AR } \\
(n=1360)\end{array}$} & \multicolumn{3}{|c|}{$\begin{array}{l}\text { Asthma } \\
(\mathrm{n}=1044)\end{array}$} & \multicolumn{3}{|c|}{$\begin{array}{l}\text { Oral allergy syndrome } \\
(n=1359)\end{array}$} \\
\hline & OR & $95 \% \mathrm{Cl}$ & $\mathrm{p}$ & OR & $95 \% \mathrm{Cl}$ & $\mathrm{p}$ & OR & $95 \% \mathrm{Cl}$ & $\mathrm{p}$ \\
\hline Age at onset of AR (years) & 1.05 & $1.00,1.086$ & 0.043 & 0.92 & $0.87,0.97$ & 0.001 & - & & \\
\hline Duration of AR since onset (by year) & 1.06 & $1.02,1.096$ & 0.004 & 1.05 & $1.00,1.09$ & 0.030 & 1.08 & $1.04,1.12$ & $<0.001$ \\
\hline Sneezers* & - & & & 1.00 & & & - & & \\
\hline Blockers $^{\dagger}$ & - & & & 1.54 & $1.09,2.18$ & 0.015 & - & & \\
\hline Central Italy & 1.00 & & & 1.00 & & & 1.00 & & \\
\hline Northern Italy & 0.42 & $0.33,0.55$ & $<0.001$ & 2.6 & $1.88,3.6$ & $<0.001$ & 1.43 & $1.08,1.89$ & 0.014 \\
\hline Southern Italy & 0.9 & $0.67,1.21$ & ns & 0.82 & $0.59,1.14$ & 0.236 & 0.63 & $0.42,0.9$ & 0.012 \\
\hline Older siblings ${ }^{\dagger}$ & 1.40 & $1.11,1.77$ & 0.004 & - & & & - & & \\
\hline Months/year with symptoms & 1.23 & $1.14,1.31$ & $<0.001$ & - & & & - & & \\
\hline Smoke father & 1.23 & $0.98,1.54$ & $<0.001$ & - & & & - & & \\
\hline Smoke mother & - & & & - & & & 1.54 & $1.16,2.06$ & 0.003 \\
\hline Female & - & & & - & & & 1.57 & $1.2,2.05$ & 0.001 \\
\hline
\end{tabular}

Variables included in the model after stepwise regression.

*Included only in the rhinitis model.

†'ncluded only in the asthma model.

Number of observations $=1044 ; \mathrm{LR} \chi^{2}=84.86 ; \mathrm{p}>\chi^{2}=0.0000$; Pseudo $\mathrm{R}^{2}=0.0605$.

OR, odd ratio 


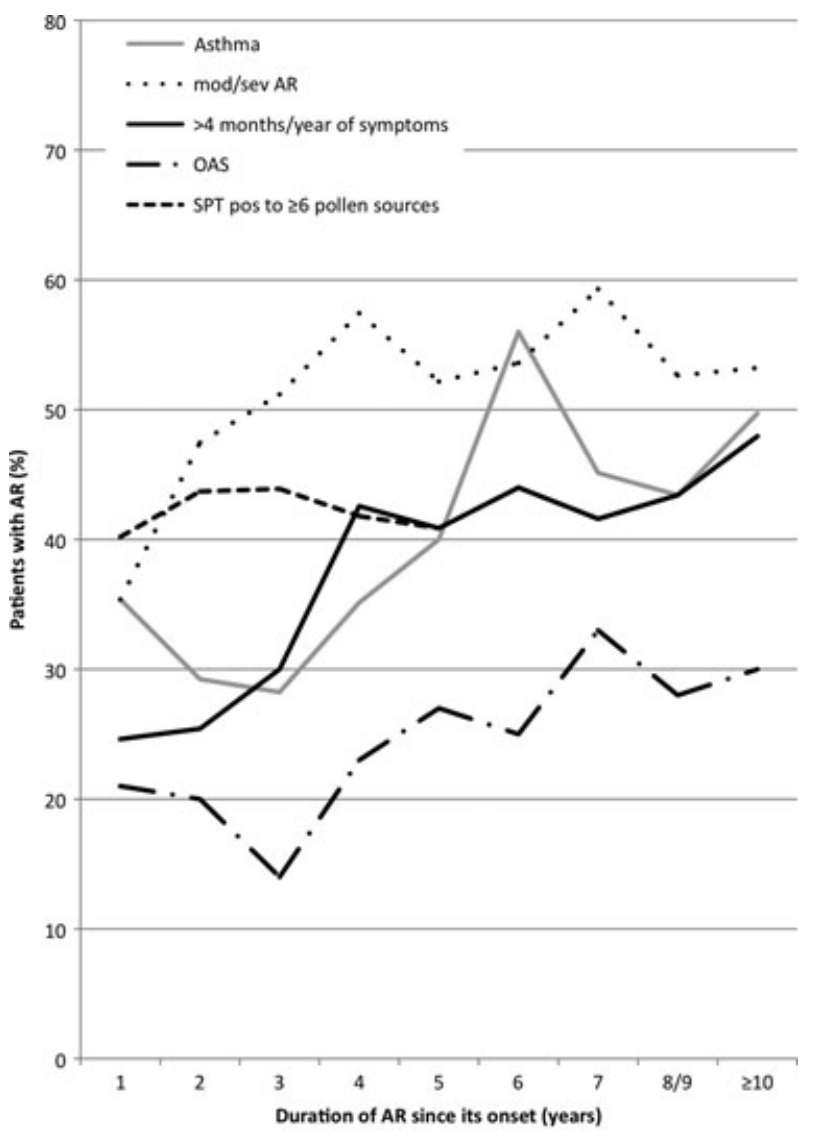

Figure 3 Probability of having moderate-to-severe allergic rhinoconjunctivitis (AR), asthma, polysensitization, and longer extension of symptoms during a year among children with $A R$, by the duration since onset of their AR.

and to pellitory and olive (higher in Southern Italy): these differences confirm previous observations, reflecting the distribution of trees and weeds species from Northern to Southern Italy and at a European, continental level (21). Not surprisingly, these differences are paralleled by differences in the frequency of OAS (higher in Northern Italy) and in the seasonal symptoms extension (longer in Southern Italy). Thus, different pollen exposures may explain why the markers of 'severity' slightly differ in Northern Italy (OAS, food-pollen syndrome) from Southern Italy (higher intensity and longer season of respiratory symptoms). To our knowledge, no other pediatric study has examined similar North-South gradients at country level in Europe and linked to markers of disease severity or comorbidities. Geographic differences of sensitization patterns in patients with respiratory allergies have been reported in Spain (22) or France (23), but they focused on coast vs. continental areas rather than a North-South gradient. Given its geographic characteristic (a country elongated from North to South), Italy can reproduce better than other countries the North-South gradients typically observed, on a wider scale, at European level.

The present analysis shows also that only a tiny minority of the patients $(6 \%)$ are pollen-monosensitized. This may have a consequence on the propensity to prescribe SIT. Recent trials showed that SIT can be effective also in pollenpolysensitized patients $(24,25)$. Nevertheless, guidelines do not recommend the administration of mixtures of different allergenic sources (26), and polysensitization is still seen by many allergists as a contraindication to SIT treatment. It could be therefore argued that many of these children would have been treated with SIT if they had seen the allergist at an earlier, mono or oligo-sensitized disease stage. On the other hand, sensitization to profilin is very frequent $(25 \%)$ in the examined population. Thus, sensitization to profilin or other highly cross-reactive 'panallergens' may contribute to explain this high frequency of heavy polysensitization (27). An obvious consequence is the need to discriminate 'genuine' from 'false' sensitizations by allergy testing based on species-specific molecules, a diagnostic approach essential for appropriate SIT prescription (28).

Our study might be influenced by some limitations. First, the population sample is not representative of the general population of children examined by allergy specialists in Italy, and although the population sample is very large, the generalizability of our conclusions may be questioned. Second, the data of age at disease onset and the consequent calculation of disease duration were obtained retrospectively in this cross-sectional study and therefore subject to potential recall bias. This bias is often associated with a so-called 'telescope' effect, i.e., the tendency to postpone the events that occurred many years before. Third, reported asthma and OAS or other food allergies could not be confirmed by lung function tests or by challenge tests, respectively, so that overreporting cannot to be excluded. However, we believe that any misdiagnosis of asthma or OAS would have contributed to confound, rather than to generate the observed associations. Fourth, sensitization to perennial allergens (house dust mites, molds, domestic animals) might have influenced the severity of pollen AR and asthma. Nevertheless, we argue that any misclassification of cases would have confounded, rather than strengthened the observed associations. On the other hand, our study has several strengths, such as the quite large population size, the broad distribution of the participating centers across Italy, the use of internationally validated diagnostic criteria and definitions, and the adoption of a common electronic platform and standardized, high-quality reagents.

In conclusion, this nationwide study demonstrates that pollen-induced AR is in an advanced stage in many children who had never received SIT against pollen and who sought care from Italian allergy clinics. The observed association between markers of pollen-induced AR severity and its duration needs to be confirmed in longitudinal studies and raises the question whether this disease and its underlying immunologic processes should be diagnosed and treated earlier in life. Our study suggests that countrywide plans for early diagnosis and intervention (already started in other European countries) (29) should be planned also in Italy and adapted to the different epidemiological characteristics of its macro-areas. 


\section{Acknowledgments}

We are in debt to Alk-Abellò for providing the reagents for the study, to TPS for the informatic platform 'Allergy$\mathrm{CARD}^{\mathrm{TM}}$, and to $\mathrm{Mr}$. Charles Clawson for revising the English language.

\section{Funding sources}

Reagents for this study have been kindly provided by ALK-Abello' (Milan, Italy; skin test reagents); the informatics platform 'AllergyCARD' ${ }^{\mathrm{TM}}$, has been kindly provided by TPS Production.

\section{Conflict of interest}

None declared.

\section{References}

1. Brozek JL, Bousquet J, Baena-Cagnani CE, et al. Allergic Rhinitis and its Impact on Asthma (ARIA) guidelines: 2010 revision. J Allergy Clin Immunol 2010: 126: 466-76.

2. Asher MI, Montefort S, Björkstén B, et al. Worldwide time trends in the prevalence of symptoms of asthma, allergic rhinoconjunctivitis, and eczema in childhood: ISAAC phases one and three repeat multicountry cross-sectional surveys. Lancet 2006: 368: 733-43.

3. Canonica GW, Bousquet J, Mullol J, Scadding GK, Virchow JC. A survey of the burden of allergic rhinitis in Europe. Allergy 2007: 62 (Suppl. 85): 17-25.

4. Fiocchi A, Fox AT. Preventing progression of allergic rhinitis: The role of specific immunotherapy. Arch Dis Child Educ Pract Ed 2011: 96 : 91-100.

5. Ingemann L. Trend in use. Report of the FASIT-Workshop 2010, 25-27 November 2010, 10p.

6. Tozzi AE, Armenio L, Bernardini R, et al. Pediatric allergy and immunology in Italy. Pediatr Allergy Immunol 2011: 22: 267-76.

7. Baldini M, Bernardini R, Berti I, et al. L'Italian Pediatric Allergy Network: Un'opportunità di ricerca per i clinici. Rivista di Immunologia e Allergologia Pediatrica 2010: 1: 32-3.

8. Tripodi S, Frediani T, Lucarelli S, et al. Molecular profiles of IgE to Phleum pratense in children with grass pollen allergy: Implications for specific immunotherapy. J Allergy Clin Immunol 2012: 129: 834-9.

9. Asher MI, Keil U, Anderson HR, et al. International Study of Asthma and Allergies in Childhood (ISAAC): Rationale and methods. Eur Respir J 1995: 8: 483-91.

10. Jáuregui I, Dávila I, Sastre J, et al. Validation of ARIA (Allergic Rhinitis and its Impact on Asthma) classification in a pediatric population: The PEDRIAL study. Pediatr Allergy Immunol 2011: 22: 388-92.
11. Bateman ED, Hurd SS, Barnes PJ, et al. Global strategy for asthma management and prevention: GINA executive summary. Eur Respir J 2008: 31: 143-78.

12. Bousquet J, Clark T, Hurd S, et al. GINA guidelines on asthma and beyond. Allergy 2007: 62: 102-12.

13. Asero R, Monsalve R, Barber D. Profilin sensitization detected in the office by skin prick test: A study of prevalence and clinical relevance of profilin as a plant food allergen. Clin Exp Allergy 2008: 38: 1033-7.

14. Bousquet J, Heinzerling L, Bachert C, et al. Practical guide to skin prick tests in allergy to aeroallergens. Allergy 2012: 67: 18-24.

15. Hatzler L, Panetta V, Lau S, et al. Molecular spreading and predictive value of preclinical IgE response to Phleum pratense in children with hay fever. J Allergy Clin Immunol 2012: 130: 894-901.

16. Niggemann B, Jacobsen L, Dreborg S, et al. Five-year follow-up on the PAT study: Specific immunotherapy and long-term prevention of asthma in children. Allergy 2006: 61: 855-9.

17. De Knop KJ, Verweij MM, Grimmelikhuijsen M, et al. Age-related sensitization profiles for hazelnut (Corylus avellana) in a birch-endemic region. Pediatr Allergy Immunol 2011: 22: e139-49.

18. Prescott S, Allen KJ. Food allergy: Riding the second wave of the allergy epidemic. Pediatr Allergy Immunol 2011: 22 : 155-60.

19. Asero R. Effects of birch pollen-specific immunotherapy on apple allergy in birch pollen-hypersensitive patients. Clin Exp Allergy 1998: 28: 1368-73.

20. Cibella F, Cuttitta G, La Grutta S, et al. Proportional Venn diagram and determinants of allergic respiratory diseases in Italian adolescents. Pediatr Allergy Immunol 2011: 22: 60-8.
21. D'Amato G, Cecchi L, Bonini S, et al. Allergenic pollen and pollen allergy in Europe. Allergy 2007: 62 : 976-90.

22. Valero A, Justicia JL, Antón E, et al. Epidemiology of allergic rhinitis caused by grass pollen or house-dust mites in Spain. Am J Rhinol Allergy 2011: 25: e123-8.

23. Migueres M, Fontaine JF, Haddad T, et al. Characteristics of patients with respiratory allergy in France and factors influencing immunotherapy prescription: A prospective observational study (REALIS). Int $J$ Immunopathol Pharmacol 2011: 24: 387-400.

24. Ciprandi G, Cadario G, Di Gioacchino GM, et al. Sublingual immunotherapy in children with allergic polysensitization. Allergy Asthma Proc 2010: 31: 227-31.

25. Ciprandi G, Incorvaia C, Puccinelli P, Soffia S, Scurati S, Frati F. Polysensitization as a challenge for the allergist: The suggestions provided by the Polysensitization Impact on Allergen Immunotherapy studies. Expert Opin Biol Ther 2011: 11: 715-22.

26. Zuberbier T, Bachert C, Bousquet PJ, et al. GA2LEN/EAACI pocket guide for allergen-specific immunotherapy for allergic rhinitis and asthma. Allergy 2010: 65: 1525-30.

27. Valenta R, Twaroch T, Swoboda I. Component-resolved diagnosis to optimize allergen-specific immunotherapy in the Mediterranean area. J Investig Allergol Clin Immunol 2007: 17 (Suppl. 1): 36-40.

28. Sastre J. Molecular diagnosis in allergy. Clin Exp Allergy 2010: 40: 1442-60.

29. Pelkonen AS, Kuitunen M, Dunder T, Reijonen T, Valovirta E, Mäkelä MJ; Finnish Allergy Programme. Allergy in children: Practical recommendations of the Finnish Allergy Programme 2008-2018 for prevention, diagnosis, and treatment. Pediatr Allergy Immunol 2012: 23: 103-16. 